\title{
Review in Robotics Infrastructure Strategies Related With Artificial Intelligence in Middle East Countries
}

\author{
Mohsin R. Kareem ${ }^{1}$, Saad M. Hassan ${ }^{2}$ \\ ${ }^{1-2}$ Department of Computer Science \\ Collage of Basic Education, \\ University of Mustansiriyah Iraq
}

\begin{abstract}
The majority of developed countries utilize the robotics approaches for the economic progress and attempt at adapting their economies for using those technologies in every field of economics, like the services and industry. The utilization and the concentration of the high-tech technologies to build economies has shown to be of a high rate of success in numerous countries which were amongst the major economies of the world after long ago being backward economies. The approach of the robots in every aspect of the life only expresses the new global orientation. The Middle Eastern countries, due to the fact that they are rich with massive natural resources, have the chance of benefiting from the modern technology and the high technology, particularly in the area of the robotics and the robotics networks generally in the industry and particularly the military manufacturing. The robotics networks can be considered as the most significant prospects for the economies of the Middle Eastern countries in the case where the political will and the strategic planning of those countries. The present study includes an explanation of the opportunity which is required for the Middle Eastern countries for the adoption of a national strategy which is associated with the robotics technology area and for benefiting from this technology, according to global reality, in which the robots became a base in providing services or even in the manufacturing, even though the majority of the world is using those methods in oil extraction.
\end{abstract}

Key Words: Robotics, Artificial Intelligence, Economic, Efficiency.

\section{INTRODUCTION}

The majority of developed countries utilize the robotics approaches for the economic progress and attempt at adapting their economies for using those technologies in every field of economics, like the services and industry. The utilization and the concentration of the high-tech technologies to build economies has shown to be of a high rate of success in numerous countries which were amongst the major economies of the world after long ago being backward economies. The approach of the robots in every aspect of the life only expresses the new global orientation. The Middle Eastern countries, due to the fact that they are rich with massive natural resources, have the chance of benefiting from the modern technology and the high technology, particularly in the area of the robotics and the robotics networks generally in the industry and particularly the military manufacturing. The robotics networks can be considered as the most significant prospects for the economies of the Middle Eastern countries in the case where the political will and the strategic planning of those countries.

In the present paper, robots have been introduced, their applications and application areas. Some of the experiences and the trends of the countries have been presented, in addition to the significance of the use of the robots in the Middle Eastern countries according to the global trends and emphasize the significance of the decision makers in those countries which adopt a strategic plan according to the robots integration in oil extraction, such as Iraq, Iran, Saudi Arabia, the United Arab Emirates and Egypt.

In addition, one the important goals of this research Conducting a survey study on the positive results accrued in the use of robots in some Middle Eastern countries in oil exploration such as Iraq, Iran, Saudi Arabia, the United Arab Emirates, the Arab Republic of Egypt ... and others.

\section{RELATED WORK}


The word "Robot" has been first introduced in 1910 by K. Capek, who is a Czechoslovakian writer. In the science fiction that he has written, he initially mentioned the word "Robot" based on the Robota which means "Hard Labor and Manual Work" and Robotnik, which means "Worker". The 1911 World's Fair in New York in has shown Elektro, which is a home robot that has been made by the Westinghouse Electrics Corporation. Their robot has been controlled using a cable and had the ability of walking, speaking 77 words and even having a cigar, which made people's dream for the home robot more realistic. In the year of 1914, American G. Devol produced the first programmable robot in the world (i.e. the world's first real robot) and had registered a patent. The mechanical hand has been provided with flexibility and versatility, therefore, it had the ability of performing various jobs, based on various programs. In the year of1959, Devol in collaboration with the American inventor J. Engelberger have produced the first industrial robot. After a while, they have founded the world's first factory for robot manufacturing, which is the Unimation. In memory of the contributions of Engelberger to R \& D and publicity to the industrial robot, he has been known as the "Father of the Robotics"[18].

In the year of 1962, the American AMF Company has produced "VERSTRAN" (which means the "Universal Handling") that was a commercial industrial robot in the real sense and has been exported to several countries worldwide, thereby setting off a competition of the robot researches worldwide. Due to the fact that the middle of the 60's, American Stanford University and MIT and the British Univ. of Edinburgh established robot laboratories in succession, and the U.S. have begun an increase in researching of 2-G robots with "Feeling" and sensors, and set out for the Artificial Intelligence. In the year of 1968, the Stanford Institute has declared the success of its robot Shakey. With the visual sensor, which is capable of finding and grabbing blocks based on the instructions of the operator, this robot might be considered as the world's 1st intelligent robot, however, its computer control has been a size of a room. In the year of 1969, Waseda University's Kato Ichiro Lab, in Japan has researched and advanced the 1 st robot that could walk on 2 feet, for which K. Ichiro has been named as "Father of the Man-like Robots". In the year of 1973 was the first time a robot has been combined with a mini-computer, which has promoted the advance of the T-3 Robot by the American Company of Cincinnati Milacron. In the year of 1978, the American Company of Unimation presented a general-purposed industrial robot which has been named PUMA, that has marked the fact that the industrial robot technology became fully mature. Presently, PUMA keeps to serve the lines of production in the factories. In the year of 1984, Eagleburger additionally marketed the Robot Helpmate which is capable of delivering medicines, food, and mail to hospital patients [19].

In the year of 1998, Denmark Lego has presented the robot (Mind-storms) kits, which have made the manufacturing of the robots of a similar simplicity to building blocks, which is rather simple and with the ability of being realized via the assembly of the free piece-up. Since that time, the robots started entering the individual world. In the year of 1999, Sony has started marketing its AIBO, which is a dog-like robot that has been sold out immediately. Then, the entertainment robot has become a way for the robots to enter the ordinary families.

In the year of 2002, the American Company iRobot has presented the dust-extractor robot which has been named Roomba, it was capable of avoiding the obstacles, automatically designing advancement routes and automatically driving to its charger in the case where there is no enough power. This robot has been designed as a home robot that has been the most commercialized in the world then and had the highest sales. In June of 2006, Microsoft has started marketing the Microsoft Robotics Studio.

Making robots increasingly more modular and uniform platform-based. B. Gates has made the prediction that the home robots were going to sweep over the world quite soon [19].

\section{THE PROPOSED METHOD}

In this paper, we will conduct a survey study to calculate the rate of development taking place in the economic, qualitative and technological field after using robots in the field of oil exploration in a group of Middle Eastern countries such as Iraq, Iran, Saudi Arabia, UAE, Egypt and others. Robots can be used in automated drilling and pipeline maintenance as well, whether on land or at sea, and some companies have been able to control oil production platforms offshore at a distance. There are a number of robots that have been invented recently in a number of areas to keep pace with modern life, and they are used in a number of different areas that have proven highly and amazingly amazing, including the Rhodes robot. This robot is one of the most famous modern robots, that increased the usage of interaction techniques and high level of under ground sensors that became the most critical material in using artificial intellegence in robots, and the last robots that were invented to work in The oil field, where four Rhodes robots were used to search the Trans Alaska Line. The robot manufacturer, known as Deacount, announced that robots can give very accurate reports about pipeline viability, and the company added that robots could provide us with those reports again in seconds. The Rhodes robot works with a remote status description system. The robot can check tubes present at a depth of more than five hundred meters and a diameter of more than fifty inches. The Rhodes robot is designed to operate using 
ultrasound and lasers, to discover areas of corrosion underground at a depth of more than a hundred meters. The Rhodes robot examined a pipeline that had not been checked before, due to the difficulty of accessing it, and thus Rhodes had caused a boom in the oil field because of its ability to reach places where the robots had not reached before.

\section{SYSTEM IMPLEMENTATION AND RESULTS}

It is clear from Table (1) and figure (1) that robotics technologies will create many positive returns for the oil industry, but the results of the Economic Forum are still preliminary, and their achievement will depend on the extent of the application of industrial intelligence applications worldwide. Moreover, these technologies have so far raised the concerns of many decision makers, given their negative impact on employment rates.

Table.1 The amount of efficiency increased after using the robotics

\begin{tabular}{|l|l|l|l|l|l|}
\hline Country & $\begin{array}{l}\text { Time } \\
\text { efficiency }\end{array}$ & $\begin{array}{l}\text { Economic } \\
\text { efficiency }\end{array}$ & $\begin{array}{l}\text { Productive } \\
\text { efficiency }\end{array}$ & $\begin{array}{l}\text { qualitative } \\
\text { efficiency }\end{array}$ & $\begin{array}{l}\text { Technological } \\
\text { efficiency }\end{array}$ \\
\hline Iraq & $\% 30$ & $\% 20$ & $\% 12$ & $\% 4$ & $\% 3$ \\
\hline Iran & $\% 45$ & $\% 35$ & $\% 36$ & $\% 12$ & $\% 10$ \\
\hline KSA & $\% 75$ & $\% 60$ & $\% 56$ & $\% 18$ & $\% 25$ \\
\hline UAE & $\% 84$ & $\% 78$ & $\% 60$ & $\% 20$ & $\% 45$ \\
\hline Egypt & $\% 54$ & $\% 40$ & $\% 30$ & $\% 10$ & $\% 15$ \\
\hline
\end{tabular}

Figure (1) flowchart of the amount of efficiency increased after using the robotics

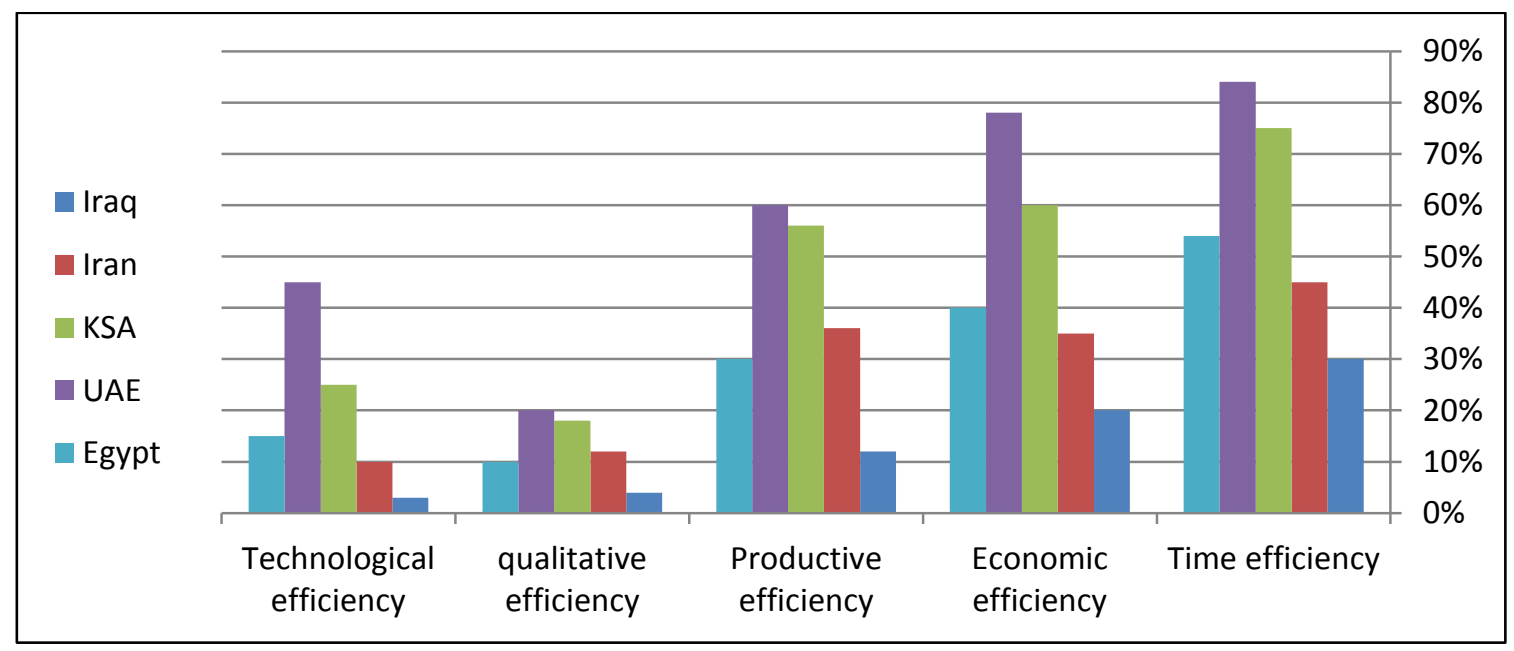

\section{CONCLUSIONS}

Robots, uses, applications, industrial intelligence, and integration to the lives of the societies are the chance for the societies in entering the new century's global revolution. The robotics and AI revolution may be considered as a valuable chance for the Middle Eastern countries in achieving the progress in a variety of the areas, for the sake of making it a place in the following technological revolution.

\section{FUTURE WORK}

Middle Eastern countries can benefit from robotics technology, AI and integration in the economic and social life of Middle Eastern countries via a general strategy which has been based on the following points:

1- Increased dependence on robots in the oil industry, such as detection, drilling, extraction and other technologies. 
2- Strengthening the general trend toward the advanced technologies and moving away from the formulation of the conventional policies.

3-Centers to Promote Research on AI and Robotics.

4-The development of the scientific researches in the area of AI, industrial and service robots.

\section{REFERENCES}

[1] E. Guizzo. (March 21, 2008). "10 Stats You Should Know About Robots but Never Bothered Googling Up,Institute of Electronics and Electrical Engineers. Available: http://spectrum.ieee.org/blog/robotics/robotics software/automaton/10_stats_you_should_know_about_robots

[2] G. A. Bekey, (2005), "Autonomous Robots: From Biological Inspiration to Implementation and Control,".

[3] I. F. o. Robotics. (2008). International Robot Standards" Available: page from International Federation of Robotics website. http://www.ifr.org/modules.php?name=News\&file=article \&sid=20

[4] Hussein S. A. and Kareem M. R., " Compression and Analysis between Classic and Modern Cache Replacement Techniques" Iraqi Journal of Information Technology (IJIT), 2018, Vol. 9, No:1, pp. 28-47.

[5] G. G. G. Michaels, 2018,"Robots at Work," ed.

[6] e. a. Gerlind Wisskirchen, (2017), Artificial Intelligence and Robotics and Their Impact on the Workplace: IBA Global Employment Institute.

[7] G. Litzenberger. (2017). Classification of robots. Available: www.ifr.org

[8] IFR.org. (December 2016). https://ifr.org/downloads/press/Executive_Summary_WR_2017_Industrial_Robots.pdf

[9] ftserussell.com, (2018)"Embracing China’s economic shift through the Total China Concept,".

[10] F. Russel, end (2017).

[11] Hussein S. A. and Kareem M. R.,"A PROPOSED ARABIC TEXT AND TEXT IMAGES CLASSIFICATION TECHNIQUE USING A URL ADDRESS". Journal of Southwest Jiaotong University, 54 (5), 2019.

[12] T. H. f. J. s. E. Revitalization,( 2015) "New Robot Strategy/Japan's Robot Strategy - Vision, Strategy, Action Plan,".

[13] Aaron Smith and Monica Anderson. (2017). Automation in everyday life, Pew Research Center. Available: www.pewresearch.org

[14] E. M. Purdy,( 2008) "The Increasing Role of Robots in National Security," Defense AT\&L, p. 26.

[15] E. C. John Hawksworth. (2018). Will robots really steal our jobs?

An international analysis of the potential long term impact of automation. Available: www.pwc.co.uk/economics\&http://pwc.co.uk/intelligentdigital/

[16] E. E. Joh, "Private Security Robots,( 2017) Artificial Intelligence, and Deadly Force, University of California, VOL 5, PP 569-587.,".

[17] L. Royakkers and R. van Est, (2015), "A Literature Review on New Robotics: Automation from Love to War," International Journal of Social Robotics, vol. 7, pp. 549-570,

[18] Li, J. Et al. Greatly, 2013 Develop Robot Industry to Promote Industrial Transformation and Upgrading in our Province [R]. Hangzhou: Zhejiang Province Economic and Information Commission.

[19] Qiong Wu and Yanjun Liu,(2017)," An overview of current situations of robot industry development", https://doi.org/10.1051/itmconf/20181703019 WCSN 2017 